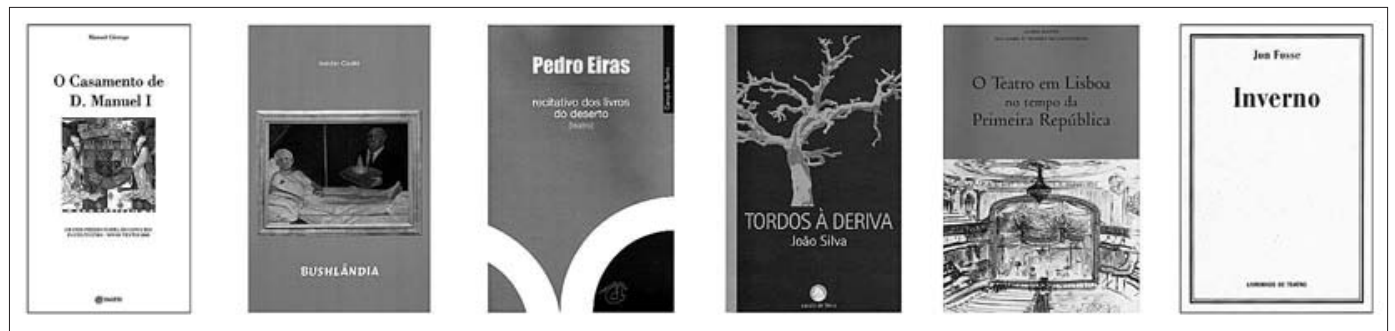

\title{
Publicações de teatro em 2004
}

\section{Lista compilada por Sebastiana Fadda}

\section{Peças originais (ou volumes de peças) em primeira edição}

CARREIRA, Laureano, O homem, Lisboa, Hugin Editores, 2004.

CÓRREGO, Manuel, 0 casamento de D. Manuel I, Lisboa, INATEL, 2004.

COSTA, Hélder, Bushlândia [Sexo, nunca mais!; A estátua de Saddam; Rato Mickey], s/l, Grafis, 2004.

COSTA, Hélder, Os Renascentistas, Lisboa, ISPA Edições, 2004.

EIRAS, Pedro, Recitativo dos livros do deserto, ilustrações do autor, Porto, Campo das Letras, Campo do Teatro, 2004.

FIGUEIRA, Jorge Louraço, Xmas qd kiseres (Christmas quando quiseres), Porto, Campo das Letras, Colecção Campo do Teatro, 2004.

LOPES, Teresa Rita, A asa e a casa, Porto, Campo das Letras e Teatro Pé de Vento, Colecção 0 Sol e a Lua, 2004.

MENDES, José Maria Vieira, T1; Se o mundo não fosse assim, Lisboa, Artistas Unidos, Livrinhos de Teatro, n. 6, 2004.

PALERMO, Raquel \& MATOS, João, De olhos fechados, Lisboa, INATEL, 2004.

PEIXOTO, José, Ensaio, Lisboa, Campo da Comunicação, Colecção Teatro, 2004.

PINHEIRO, Sandra, Emprateleirados, Lisboa, INATEL, 2004.

PIRES, Jacinto Lucas, Figurantes e outras peças [Coimbra B; Os dias de hoje], Lisboa, Edições Cotovia, Teatro, 2004.

REVEZ, António Manuel, O frio que faz na cama, s/l [Mem Martins], Coolbooks, 2004.

REVEZ, António Manuel, Maravilhoso mundo novo, Coimbra, Mar da Palavra, Colecção Alquimias, 2004.

ROCHA, Natércia, Vamos todos ao teatro, ilustrações de Isabel Pissarra, Lisboa, Dinalivro, 2004.

ROSA, Armando Nascimento, A última lição de Hipátia, seguido de 0 túnel dos ratos, Porto, Campo das Letras, Colecção Campo do Teatro, 2004.

SILVA, João, Tordos à deriva, Lisboa, Cavalo de Ferro, 2004.

SIMÕES, J.P., Ópera do falhado, prefácio de João Lourenço, Lisboa, 101 Noites Criação de Produtos Culturais, Colecção Poiesis, 2004.

VIEIRA, Vergílio Alberto, Pára-me de repente, prefácio de Manuel Lourenzo, Lisboa, Editorial Caminho, Campo da Palavra, Teatro, 2004

VITORINO, Ana / COSTA, Carlos / MARTINS, Catarina / CARREIRA, Pedro, Estudos e Orla do bosque, Caderno II, s/l, Visões Úteis, 2004.
VITORINO, Ana / COSTA, Carlos / MARTINS, Catarina, 667: O vizinho da besta, prefácio de Eduardo Condorcet, Vila Nova de Famalicão, Quasi, Biblioteca Aquela Vez, 2004.

\section{Peças em reedição}

BARBOSA, Pedro, Há alguém aí? Monólogo para três actores (2a edição, revista e alterada, de Anticleia ou os chapéus de chuva do sonho, 1a edição em 1992) / Sacrilégio teatral: Rito e mito (2a edição, revista e alterada, de Eróstrato, 1a edição em 1984), Porto, Edições Afrontamento, Colecção de Teatro, n. 9, 2004.

CAMÕES, Luis de, Filodemo, edição de José Camões, Lisboa, Edições Cotovia, Teatro, 2004.

CURTO, Ramada, Teatro escolhido [vol. I: O estigma (1905), O redentor da llíria (1916), 0 caso do dia (1926), 0 homem que se arranjou (1928), Demónio (1928)], introdução, pesquisa e análise crítica de Duarte Ivo Cruz, Lisboa, Imprensa Nacional-Casa da Moeda, Biblioteca de Autores Portugueses, 2004

CURTO, Ramada, Teatro escolhido [vol. II: A cadeira da verdade (1932), Mascarada (1933), Recompensa (1938), As meninas da Fonte da Bica (1948), Fogo de vista (1956)], Lisboa, Imprensa Nacional-Casa da Moeda, Biblioteca de Autores Portugueses, 2004.

FONTES, Martins, Partida para Cythera. Alta comédia em 3 actos ( $2^{a}$ edição para a edição portuguesa, $1^{\text {a }}$ edição em 1925), organização, coordenação, prefácio e notas de Rui Calisto, Caldas da Rainha, CCCA - Cooperativa Cultural Companhia das Artes Crl, 2004

GARRET, Almeida, Frei Luís de Sousa, prefácio de António Mega Ferreira, s/l [Cacém], Texto Editora, Colecção Clássicos Lidos por Contemporâneos, 2004.

GARRETT, Almeida, Frei Luis de Sousa, prefácio de Annabela Rita, Porto, Edições Caixotim, Colecção Obras de Almeida Garrett, 2004.

LIMA, Mesquitela (ed.), Vai-te treinando desde já: Peça de teatro de João Cleofas Martins (Nhô Djunga), edição comentada por Mesquitela Lima, Lisboa, Nova Vega Lda, Colecção Palavra Africana / Ficção, 2004.

MONTEIRO, Luís de Sttau, Felizmente há luar, s/l [Porto], Areal Editores, 2004. 

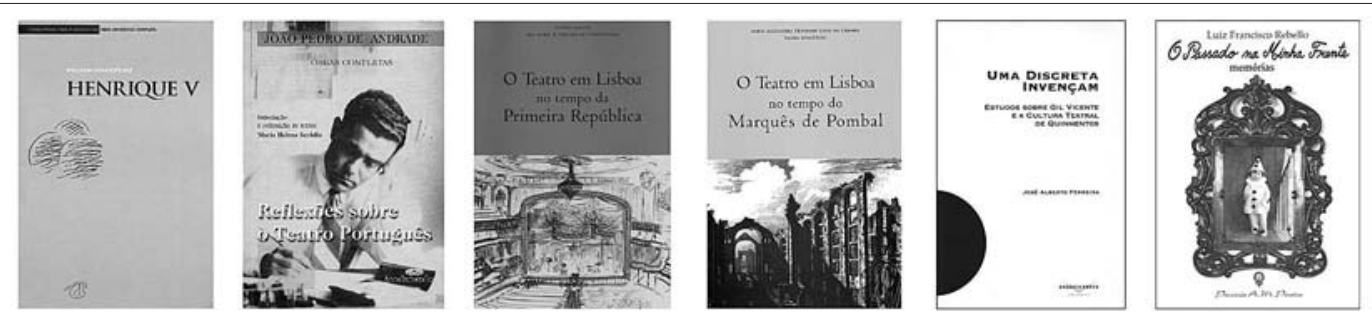

\section{Traduções}

BERNHARD, Thomas, O fazedor de teatro, trad. José A. Palma Caetano, Lisboa, Assírio \&t Alvim, 2004.

BRECHT, Bertolt, Teatro 2 [A vida de Eduardo // de Inglaterra; Um homem é um homem; Ascensão e queda da cidade de Mahagonny; A ópera de três vinténs], introdução de Vera San Payo de Lemos; trad. Manuel Resende (A vida de Eduardo // de Inglaterra), António Conde (Um homem é um homem), João Lourenço e Vera San Payo de Lemos (Ascensão e queda da cidade de Mahagonny); João Lourenço e Vera San Payo de Lemos, com a colaboração de José Fanha nas canções ( $A$ ópera de três vinténs), Lisboa, Edições Cotovia, 2004.

FOSSE, Jon, A noite canta os seus cantos, trad. Pedro Fernandes e Manuel Resende, Lisboa, Artistas Unidos, Colecção Livrinhos de Teatro, n. ${ }^{\circ}$ 4, 2004.

LAGARCE, Jean-Luc, Tão só o fim do mundo; As regras de bem viver na sociedade moderna; Estava em casa e esperava que a chuva viesse, trad. Alexandra Moreira da Silva, Lisboa, Artistas Unidos, Colecção Livrinhos de Teatro, n. ${ }^{\circ}$ 7, 2004.

ORTON, Joe, 0 nosso hóspede; A saque, trad. Manuel João Gomes ( 0 nosso hóspede) e Francisco Luis Parreira e Alcides Estrela (A saque), Lisboa, Artistas Unidos, Colecção Livrinhos de Teatro, n. 5, 2004.

SHAKESPEARE, William, Comédia de equivocos, trad., introdução e notas por Maria Cândida Zamith, Porto, Campo das Letras, Colecção Shakespeare para o Século XXI: Obra Dramática Completa, 2004.

SHAKESPEARE, William, Henrique $V$, trad., introdução e notas por M. Gomes da Torre, Porto, Campo das Letras, Coleç̧ão Shakespeare para o Século XXI: Obra Dramática Completa, 2004.

SHAKESPEARE, William, Titus Andronicus, trad. e posfácio de José Miguel da Silva, Lisboa, Relógio d'Água, Colecção Teatro, 2004.

\section{Estudos / Documentos}

ANDRADE, João Pedro de, Reflexões sobre o teatro, introdução e ordenação de textos por Maria Helena Serôdio, Lisboa, Acontecimento Estudos e Edições Lda, Colecção Obras Completas, 2004.

ASSIS, Maria de / Spångberg, Mårten (ed.), Capitals, Lisboa, Fundação Calouste Gulbenkian, 2004.

BASTOS, Glória / VASCONCELOS, Ana Isabel P. Teixeira, 0 teatro em Lisboa no tempo da Primeira República, Lisboa, Museu Nacional do Teatro, Colecção Páginas de Teatro, 2004.

BENJAMIN, Walter, Obras escolhidas: A origem do drama trágico alemão, edição, apresentação e trad. João Barrento, Lisboa, Assírio \&t Alvim, 2004.

CABRAL, Carlos, Manual de técnicas de palco, Lisboa, INATEL, 2004.

CÂMARA, Maria Alexandra Trindade Gago da / ANASTÁCIO, Vanda, 0 teatro em Lisboa no tempo do Marquês de Pombal, Lisboa, Museu Nacional do Teatro, Colecção Páginas de Teatro, 2004.

CORREIA, André de Brito, Arte como vida e vida como arte: Sociabilidades num contexto de criação artística, Porto, Edições Afrontamento, 2004.

CORREIA, Palmira, Ruy de Carvalho: O grande senhor do teatro, prefácio de Paulo Mira Coelho, Porto, Publicações D. Quixote, 2004.

DOS SANTOS, Graça, 0 espectáculo desvirtuado: 0 teatro português sob o reinado de Salazar (1933-1968), trad. Lígia Calapez, prefácio de Maria Helena Serôdio, Lisboa, Editorial Caminho, Colecção Universitária, 2004.

FERREIRA, José Alberto, Uma discreta invençam. Estudos sobre Gil Vicente e a cultura teatral de Quinhentos, Coimbra, Angelus Novus, 2004.

GONÇALVES, Jorge, Até aos olhos: Fotografias de cena, prefácio de Jorge Silva Melo, Lisboa, Artistas Unidos, 2004.

LOURENÇO, Frederico, Grécia revisitada, Lisboa, Edições Cotovia. 2004.

MARTINHO, Fernando J.B. (coordenação de), Literatura portuguesa do século XX, ensaios de Fernando J.B. Martinho (poesia), Fernando Pinto do Amaral (narrativa), Maria Helena Serôdio (dramaturgia) e Serafina Martins (ensaio literário), Lisboa, Instituto Camões, 2004.

MELO, António Maria Martins, Teatro jesuítico em Portugal no século XVI. A tragicomédia Josephus do $P$. L Luís da Cruz, S.J., Lisboa, Fundação Calouste Gulbenkian, Fundação da Ciência, Ministério da Ciência e do Ensino Superior, Colecção Textos Universitários de Ciências Sociais e Humanas, 2004.

REBELLO, Luiz Francisco, O palco virtual, Porto, Edições Asa, Colecção Ensaio, 2004.

REBELLO, Luiz Francisco, O passado na minha frente: Memórias, Lisboa, Parceria A. M. Pereira, 2004.

REIS, Luciano, História do circo: Familias e modalidades, Lisboa, Sete Caminhos, 2004.

SANTOS, Maria de Lourdes Lima dos (coordenação), Políticas culturais e descentralização: impactos do programa de difusão das artes de espectáculo, autores: Maria de Lourdes Lima dos Santos, Rui Telmo Gomes, José Soares Neves, Maria João Lima, Vanda Lourenço, Teresa Duarte Martinho, Jorge Alves dos Santos, Marta Araújo, Sara Duarte, Tânia Leão, Joana Saldanha Nunes e Rita Rosado; coordenação técnica de António Martinho Novo; Lisboa, Observatório das Actividades Culturais, 


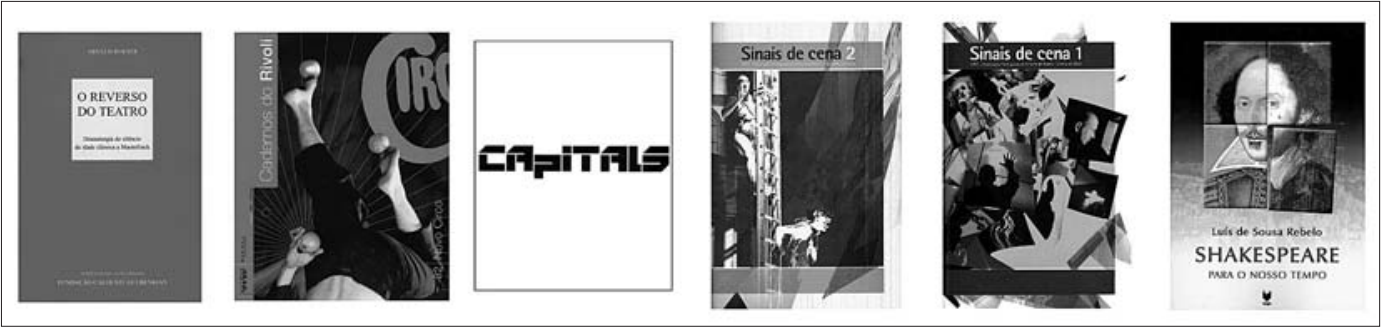

Colecção Obs Pesquisas, n. ${ }^{\circ}$ 12, 2004

RYKNER, Arnaud, 0 reverso do teatro: Dramaturgia do silêncio da idade clássica a Maeterlinck, trad. Dóris Graça Dias, Lisboa, Fundação Calouste Gulbenkian, 2004.

TRIGO, Jorge / REIS, Luciano, Parque Mayer: 1922-1952, vol. I, Lisboa, Sete Caminhos, 2004.

VASCONCELOS, Ana Isabel P. Teixeira, 0 teatro em Lisboa no tempo de Almeida Garrett, Lisboa, Museu Nacional de Teatro, Colecção Páginas de Teatro, 2004.

\section{Publicações periódicas}

Artistas Unidos: Revista, n. `s 10 (Março de 2004), 11 (Julho de 2004) e 12 (Novembro de 2004), dir. Jorge Silva Melo, Lisboa, Livros Cotovia.

Cadernos Rivoli, n. ${ }^{\circ}$ 2: Novo circo, dir. Marcelo Mendes Pinto, coordenação editorial de Isabel Alves Costa, Porto, Culturporto - Associação de Produção Cultural, 2004, 96 pp.

Duas Colunas, n. ${ }^{\circ} 8$ (Janeiro de 2004), 9 (Fevereiro de 2004), 10 (Março de 2004), 11 (Maio de 1004), 12 (Junho de 2004) e 13 (Setembro de 2004), dir. José Luis Ferreira, ed. João Luis Pereira, Porto, Teatro Nacional S. João.

Sinais de cena, n. 1 (Junho de 2004), revista da Associação Portuguesa de Críticos de Teatro / Centro de Estudos de Teatro, Porto, Campo das Letras.

Sinais de cena, n. 2 (Dezembro de 2004), revista da Associação Portuguesa de Críticos de Teatro / Centro de Estudos de Teatro, Porto, Campo das Letras.

\section{PUBLICAÇÕES DE TEATRO EM 2003}

Adenda à lista publicada em Sinais de cena $n .^{\circ} 1$

REBELO, Luis de Sousa, Shakespeare para o nosso tempo, Lisboa, Veja, 2003. [ensaio]

SANTOS, Odete, Em Maio há cerejas: Tragicomédia em dois actos e um epilogo, Vila Nova de Gaia, Editora Ausência, 2003. [peça]

VITORINO, Ana / COSTA, Carlos / MARTINS, Catarina / CARREIRA, Pedro, Visiveis na estrada através da orla do bosque [e Viagem partilhada], prefácio de Luiz Francisco Rebello, Vila Nova de Famalicão, Visões Úteis e Edições Quasi, Biblioteca Aquela Vez, 2003. [ensaio] 